TITLE:

\title{
Atrophy of the lower limbs in elderly women: is it related to walking ability?
}

\section{$\operatorname{AUTHOR}(S)$ :}

Ikezoe, Tome; Mori, Natsuko; Nakamura, Masatoshi; Ichihashi, Noriaki

\section{CITATION:}

Ikezoe, Tome ... [et al]. Atrophy of the lower limbs in elderly women: is it related to walking ability?. European journal of applied physiology 2011, 111(6): 989-995

\section{ISSUE DATE:}

2011-06

URL:

http://hdl.handle.net/2433/142588

\section{RIGHT:}

The final publication is available at www.springerlink.com; この論文は 出版社版でありません。引用の際には出版社版をご確認ご利用くださ $\omega_{\circ}$; This is not the published version. Please cite only the published version. 


\section{Article title:}

Atrophy of the lower limbs in elderly women: is it related to walking ability?

\section{The names of the authors}

5 Tome Ikezoe, Natsuko Mori, Masatoshi Nakamura, Noriaki Ichihashi

\section{The affiliations and addresses of the authors}

Tome Ikezoe, Natsuko Mori, Masatoshi Nakamura, Noriaki Ichihashi

Human Health Sciences, Graduate School of Medicine, Kyoto University, 53 Shogoin

10 -Kawahara-cho, Sakyo-ku, Kyoto 606-8507, Japan

The e-mail address, telephone and fax numbers of the corresponding author

telephone: $+81-75-751-3964 \quad$ fax numbers: $+81-75-751-3909$

E-mai: ikezoe@hs.med.kyoto-u.ac.jp

15 Abstract

This study investigated the relationship between walking ability and age-related muscle atrophy of the lower limbs in elderly women. The subjects comprised 20 young women and 37 elderly women who resided in nursing homes or chronic care institutions. The elderly subjects were divided into 3 groups according to their walking ability. The muscle thickness of the following

2010 lower limb muscles were measured by B-mode ultrasound: the gluteus maximus, gluteus medius, gluteus minimus, psoas major, rectus femoris, vastus lateralis, vastus intermedius, biceps femoris, gastrocnemius and soleus. Compared to the young group, muscle thicknesses of all muscles except the soleus muscle were significantly smaller in all the elderly groups. There were no significant differences between the fast- and slow-walking groups in the thickness of any muscle. In the dependent elderly group, noticeable muscle atrophy was observed in the quadriceps femoris muscle. The results of this study suggest that the elderly who are capable of locomotion, regardless of their walking speed, show a moderate degree of age-related atrophy, while those who do not walk exhibit more severe atrophy, especially in the quadriceps femoris muscle.

30 Key words

Aging, Muscle atrophy, Ultrasonography, Lower limb muscles, Elderly women

\section{Conflict of interest: None.}

35 Contact information for corresponding authors

Tome Ikezoe

Human Health Sciences, Graduate School of Medicine, Kyoto University, 53 Shogoin -Kawahara-cho, Sakyo-ku, Kyoto 606-8507, Japan

E-mai: ikezoe@hs.med.kyoto-u.ac.jp

40 telephone : +81-75-751-3964

fax numbers : +81-75-751-3909 
Atrophy of the lower limbs in elderly women: is it related to walking ability?

Tome Ikezoe $^{1)}$, Natsuko Mori ${ }^{1)}$, Masatoshi Nakamura ${ }^{1)}$, Noriaki Ichihashi ${ }^{1)}$

1) Human Health Sciences, Graduate School of Medicine, Kyoto University

\section{Abstract}

This study investigated the relationship between walking ability and age-related muscle atrophy of the lower limbs in elderly women. The subjects comprised 20 young women and 37 elderly women who resided in nursing homes or chronic care institutions. The elderly subjects were divided into 3 groups according to their walking ability. The muscle thickness of the following 10 lower limb muscles were measured by B-mode ultrasound: the gluteus maximus, gluteus medius, gluteus minimus, psoas major, rectus femoris, vastus lateralis, vastus intermedius, biceps femoris, gastrocnemius and soleus. Compared to the young group, muscle thicknesses of all muscles except the soleus muscle were significantly smaller in all the elderly groups. There were no significant differences between the fast- and slow-walking groups in the thickness of any muscle. In the

15 dependent elderly group, noticeable muscle atrophy was observed in the quadriceps femoris muscle. The results of this study suggest that the elderly who are capable of locomotion, regardless of their walking speed, show a moderate degree of age-related atrophy, while those who do not walk exhibit more severe atrophy, especially in the quadriceps femoris muscle.

\section{$20 \quad$ Key words}

Aging, Muscle atrophy, Ultrasonography, Lower limb muscles, Elderly women

\section{Introduction}

Skeletal muscle mass decreases as people age, and it decreases by 30-50\% between the ages of 40 and 80 years (Akima et al. 2001; Allen et al. 1960; Lexell et al. 1988; Young et al. 1985). Muscle atrophy is reported to be greater in the lower limbs than in the upper limbs (Bemben et al. 1991; Brooks and Faulkner 1994; Janssen et al. 2000; Kubo et al. 2003a). Kubo et al. (2003a) reported that relative muscle thickness of the vastus lateralis and medial gastrocnemius muscles, as measured by B-mode ultrasound, decreased significantly with advancing age, whereas no significant age-related change in relative muscle thickness was observed for the triceps brachii muscle.

In recent years, there have been many studies on age-related atrophy (sarcopenia) of lower limb muscles using ultrasonographic measurement of muscle thickness. However, in these studies, the quadriceps (Arts et al. 2010; Kubo et al. 2003a, 2003b; Reimers et al. 1998) and triceps surae muscles (Fujiwara et al. 2010; Kubo et al. 2003a, 2003b; Reimers et al. 1998) have been mainly evaluated. There have been no studies that have focused on sarcopenia in the individual muscles of the lower limb, including those around the hip, knee and ankle joints.

Loss of skeletal muscle mass is part of the ageing process and is exacerbated by inactivity (Sandler et al. 1991). However, there is evidence that older adults, even frail older adults, can increase muscle mass with exercise (Macaluso and De Vito 2004). In this way, the degree of daily 
physical activity influences the amount of muscle mass, especially in the elderly.

It has been pointed out that daily physical activity in the elderly is closely associated with their walking ability, such as the amount of walking that they do on a daily basis. For example, Park et al. (2010) demonstrated that muscle mass in the lower limbs of older adults, as measured by whole-body dual X-ray absorptiometry, is associated with physical activity such as the walking step count in daily life. Conversely, a previous study that measured thigh muscle volume using magnetic resonance imaging (MRI) showed decreases in muscle mass in the early stage after a 7-day period of strict bed rest that prohibited weight-bearing activity such as locomotor activity (Ferrando et al. 1995). However, it is unclear whether sarcopenia of individual lower limb muscles is related to walking ability in the elderly.

The aim of this study was to investigate the relationship between walking ability and sarcopenia of the lower limbs using ultrasound.

\section{Methods}

\section{Subjects}

The subject groups were comprised of 20 healthy young women (age, $19.8 \pm 0.8$ years; height, $1.58 \pm 0.06 \mathrm{~m}$; weight, $53.8 \pm 5.0 \mathrm{~kg}$ ) and 37 elderly women $(85.5 \pm 6.3$ years; $1.44 \pm 0.07 \mathrm{~m} ; 41.1$ $\pm 9.0 \mathrm{~kg}$ ). The young subjects were healthy university student volunteers. All subjects were physically active but did not include athletes. All elderly subjects were residents of nursing homes or chronic care institutions in Kyoto, Japan. We excluded elderly subjects who had an unstable physical condition, a history of lower extremity surgery or physical dysfunctions, such as acute neurological impairment (acute stroke, Parkinson's disease, paresis of the lower limbs), or a severe musculoskeletal impairment, such as limited range of motion of the lower limbs.

The elderly subjects were divided into 3 groups according to their walking ability: (1) a fast-walking group of elderly persons who were able to walk independently or with an assistive device at a maximum walking speed of more than $1 \mathrm{~m} / \mathrm{s}$-this speed has been considered to be the cut-off value that predicts a risk of falls in older people (Shimada et al. 2009);, (2) a slow-walking group of elderly persons who were able to walk independently or with an assistive device at a maximum walking speed of less than $1 \mathrm{~m} / \mathrm{s}$ and (3) a dependent group of elderly persons who were

30 able to maintain a sitting position in a wheelchair but were not able to walk independently and had not walked for more than half a year. Table 1 shows the characteristics of the 3 elderly groups. No significant differences were found between elderly groups in age and height.

The subjects were informed about the study procedures before testing and provided a written informed consent before participating. The study was approved by Kyoto University Graduate

35 School and Faculty of Medicine Ethics Committee.

\section{Muscle thickness measurements}

Using B-mode ultrasound imaging (LOGIQ Book Xp; GE Healthcare Japan, Tokyo, Japan) with an $8-\mathrm{MHz}$ transducer, lower limb muscle thicknesses on the longitudinal plane were measured (Figure 1). Strong correlations have been reported between muscle thickness measured by B-mode 
ultrasound and site-matched skeletal muscle mass measured by MRI (Dupont et al. 2001; Fukunaga et al. 2001; Miyatani et al. 2004; Sanada et al. 2006; Walton et al. 1997). Therefore, it is plausible to use muscle-thickness measurements to estimate muscle size and degree of muscle atrophy.

Ten muscles in the lower limbs were examined: the gluteus maximus, gluteus medius, gluteus minimus, psoas major, rectus femoris, vastus lateralis, vastus intermedius, biceps femoris, gastrocnemius and soleus. We examined the muscles on the right lower limbs of subjects. Measurement positions and measurement sites for each muscle are shown in Table 2. During the examination, care was taken to maintain the same standardized position of the subjects and the exact location of the transducer. To improve acoustic coupling, a water-soluble transmission gel was placed over the scan head. The transducer was held perpendicular to the skin surface using the minimum pressure required to achieve a clear image. Muscle thickness was measured by the examiner who was blinded with respect to the subjects' walking ability, such as walking speed.

A previous study has shown the reliability of the ultrasound technique for measuring muscle thickness of the quadriceps femoris (Blazevich et al. 2006; Thoirs and English 2009), hamstring

15 (Kellis et al. 2009; Thoirs and English 2009) and triceps surae muscles (Maganaris et al. 1998; Narici et al. 1996). However, the reliability of the measurements of the gluteus maximus, gluteus medius, gluteus minimus and psoas major muscles has not been shown before. Therefore, the reliability of the measurements of these muscles was assessed in a pilot study. Sixteen healthy volunteers (mean age, 20.3 years; SD, 0.49) were recruited for the reliability analysis. The intraclass correlation coefficients (ICC) for the test-retest reliability of the muscle thickness measurements were 0.991 (95\% CI: 0.974-0.997) for the gluteus maximus, 0.990 (95\% CI: 0.971-0.996) for the gluteus medius, 0.965 (95\% CI: 0.900-0.988) for the gluteus minimus and 0.968 (95\% CI: $0.910-0.989$ ) for the psoas major muscles; these results indicated a high degree of reproducibility in measuring muscle thickness of these muscles.

\section{Statistical analyses}

All data are presented as mean $\pm \mathrm{SD}$. We calculated the magnitude of age-related decline compared to the young reference group using the following formula: Magnitude of age-related decline $(\%)=($ mean thickness in the young - muscle thickness in the elderly $) \times($ mean thickness in the young $)^{-1} \times 100$.

Furthermore, we calculated the t-scores to take into account the variability in muscle thickness between muscles in the young reference group. The t-score was calculated using the following equation: $\mathrm{t}$-score $=$ (muscle thickness in the elderly - mean thickness in the young $) \times(\mathrm{SD}$ of thickness in the young $)^{-1}$.

35 Differences in muscle thickness and the magnitude of age-related decline between groups (the young, fast-walking, slow-walking and dependent groups) were examined using the Kruskal-Wallis test. If a significant main effect was found, differences among muscle thickness or magnitude of decline were determined with the Steel-Dwass post-hoc test. Differences in the t-score between muscles were examined using Friedman's test and a multiple comparison method (Steel-Dwass test). 


\section{Results}

\section{Comparison of muscle thickness $(\mathrm{mm})$ between the young and elderly groups}

Table 3 shows the mean and standard deviation values of muscle thicknesses for the young and

the 3 elderly groups. Statistical analysis revealed a significant main effect for all muscles ( $<$ < 0.01). When the muscle thicknesses were compared between the young and elderly groups, all muscles except the soleus muscle, i.e. the gluteus maximus, gluteus medius, gluteus minimus, psoas major, rectus femoris, vastus lateralis, vastus intermedius, biceps femoris and gastrocnemius, were significantly thinner in all the elderly groups. As for the soleus muscle, although there was a significant difference between the young and dependent elderly groups, no differences were found between the young as well as fast- and slow-walking elderly groups.

\section{Comparison of the magnitude of age-related decline $(\%)$ between the elderly groups}

Table 4 shows the magnitude of age-related decline (\%) in the elderly groups. When the magnitude of age-related decline was compared between the 3 elderly groups, there were no significant differences in magnitude of decline of any muscle between the fast- and slow-walking groups. Significant differences were found between the dependent group and the 2 walking groups in the magnitude of decline of gluteus maximus, gluteus medius, rectus femoris, vastus lateralis, vastus intermedius, biceps femoris, gastrocnemius and soleus. There were no significant differences in magnitude of decline between the 3 elderly groups in the gluteus minimus and psoas major muscles.

\section{Differences in the t-score between muscles in the elderly groups}

Table 5 shows the t-score of muscle thickness in the elderly groups. The t-score of muscle thickness in the fast-walking group was the highest for the soleus muscle, followed in order by the gluteus minimus, gluteus medius, vastus intermedius, rectus femoris, gastrocnemius, vastus lateralis, gluteus maximus, biceps femoris and psoas major muscles. The Friedman test indicated that there was a significant main effect on all muscles in the fast walking group ( $p<0.01)$.

The t-score of muscle thickness in the slow-walking group was the highest for the soleus muscle, followed in order by the gluteus minimus, gluteus medius, rectus femoris, gastrocnemius, vastus intermedius, vastus lateralis, gluteus maximus, psoas major and biceps femoris. The Friedman test revealed a significant main effect for muscle in the slow-walking group $(\mathrm{p}<0.05)$.

The t-score of muscle thickness in the dependent group was the highest for the gluteus minimus, followed in order by the gluteus medius, soleus muscle, gastrocnemius, psoas major, gluteus maximus, vastus intermedius, biceps femoris, rectus femoris and vastus lateralis. The Friedman test revealed a significant main effect for muscle in the dependent group $(\mathrm{p}<0.01)$. The post hoc test used to compare the the t-score of muscle thickness in the dependent group showed that the quadriceps group of muscles, such as the vastus lateralis and rectus femoris, has significantly smaller values than gluteus minimus, gluteus medius, soleus or gastrocnemius. 


\section{Discussion}

There were 2 main findings in this study. First, sarcopenia was lowest for the soleus muscle among the 10 muscles of the lower limbs in the elderly who were able to walk independently. Second, a larger magnitude of age-related decline occurred in the quadriceps group of muscles than

in other muscles among the lower limb muscles in the elderly who could not walk independently. To our knowledge, this is the first report showing sarcopenia of individual muscles constituting the lower limb muscles, including those around the hip, knee and ankle joint. In addition, this is the first report showing the relationship between sarcopenia and walking ability in elderly women.

In this study, the measurement of the thickness of 10 muscles of the lower limbs showed the smallest degree of atrophy in the soleus muscle in the elderly groups. In addition, no significant difference was seen in the soleus muscle thickness between the young and walking elderly groups. Our findings showed only slight age-related changes of the soleus muscle in elderly people who were able to do ambulatory activity. In general, greater rates of age-related loss occur among type II fibres, whereas only moderate losses occur among type I fibers (Doherty et al. 1993; Lexell et al. 1988; Roos et al. 1997). Therefore, the postural role of the soleus muscle in the elderly people who were able to do ambulatory activity may protect this muscle from marked reductions in thickness with ageing, given its predominant type I composition (Johnson et al. 1973).

Our analyses of the comparison between the elderly groups indicated no difference between the fast- and slow-walking groups in magnitude of decline of all muscles. Previous studies reported that maximum walking speed in the elderly was closely associated with their muscle strength in the lower limbs. However, the relationship between walking speed and muscle strength was non-linear; i.e. there was a threshold value of muscle strength at which walking speed could not improve even if muscle strength increased (Buchner et al. 1996; Ferrucci et al. 1997; Kwon et al. 2001; Rantanen et al. 1998). Our results suggest that elderly women in the slow-walking group had enough muscle mass to give muscle force at the constant standard. We believe that factors other than muscle mass, such as balance control or motor coordination, may contribute to the difference in walking speed between the fast- and slow-walking groups.

30 Although the magnitude of decline of muscle thickness in the dependent elderly group was 49.1-83.0\% greater than that in the walking elderly groups, there were no significant differences between the 3 elderly groups in magnitude of decline of the gluteus minimus and psoas major muscles. These results suggest that despite the marked reduction of overall muscle thickness in the elderly women who did not engage in walking for a long period, a relatively smaller degree of atrophy was found in their deep hip muscles. Studies on rats have frequently reported that experimental cast immobilization results in preferential reduction in slow-twitch muscle mass (Booth. 1982; Ohira et al. 1992; Templeton et al. 1988), whereas it was noted that greater decrease of human fast-twitch muscle mass occurred in skeletal muscle as a result of inactivity (Hikida et al. 1989). Because the mass of skeletal muscle is located in a deep part of the muscle and a large 
muscles of the hip joint, such as the gluteus minimus and psoas major muscles, even among elderly who do not engage in locomotor activity. Deep muscles in close proximity to a hip joint are believed to provide joint stability (Andersson et al. 1995). Gravity generates muscle loading at the hip joint during sitting activities, which may lead to lesser atrophy in the deep hip muscles even for the elderly who do not engage in locomotor activities. Hide et al. (2007) also reported that cross-sectional area (CSA) of the multifidus, as measured by MRI, decreased by day 14 of bed rest in healthy male subjects, whereas that of the psoas muscle increased. This may reflect muscle shortening during bed rest. The results of that study suggest that changes in muscle architecture, such as muscle shortening resulting from a long period inactivity may also influence the degree of muscle atrophy.

The $\mathrm{t}$-score of muscle thickness in the dependent elderly group was the lowest for quadriceps femoris such as vastus lateralis and rectus femoris, suggesting particularly marked changes relative to walking disability in this muscle among muscles of the lower limb. Reduced physical activity leads to a loss of skeletal muscle mass. Lower limb muscles, especially antigravity muscles such as the quadriceps femoris that are required for weight-bearing activities (i.e. walking, stair climbing), are likely to be affected most by reduced gravitational loading and inactivity (bed rest). Previous studies have documented that human muscle mass in the quadriceps femoris was reduced by $3 \%$ after 7 days (Ferrando et al. 1995), 8\% after 20 days (Akima et al. 1997) and 14\% after 42 days (Berg et al. 1997) of bed rest. Thus, loss of skeletal muscle mass is exacerbated by periods of inactivity or bed rest. In the present study, a significant impact on muscle atrophy might have been observed in the quadriceps femoris muscle due to inactivity caused by physical disability, because dependent elderly group did not engage in weight-bearing activities for an extended period of time.

This study had some limitations. One limitation arose from measurement of the muscle thickness for determining the muscle mass of lower limb muscles. In general, the muscle cross-sectional area is assumed to reflect muscle strength. In this study, the muscle thickness in the longitudinal axis was measured. However, the obtained measurement values did not reflect the transverse axis.

30 The other limitation of this study was the small number of subjects. The stringent exclusion criteria, which limited the number of subjects, may also limit the generalisability of the findings.

Another limitation arose from the cross-sectional structure of this study. Thus, for noticeable muscle atrophy of quadriceps femoris in the dependent elderly group, the causality was not clear; i.e. whether muscle atrophy of quadriceps femoris progressed as a result of inactivity or whether muscle atrophy of quadriceps femoris led to disability. In addition, the inclusion criterion for the dependent group selected elderly women who had not walked for more than a half year, which was not standardized as the period when they were not walking.

Further longitudinal studies are required to clarify the association between the degree of 
the present study.

\section{Conclusions}

We found that the fast- and slow-walking elderly groups showed the same extent of atrophy,

while the dependent elderly group showed more severe atrophy. This study suggested that sarcopenia in the lower limbs was least for the soleus muscle in the elderly women who were able to walk independently, and that muscle atrophy in the quadriceps group of muscles was at a maximum in the elderly who had not walked for a long period of time.

\section{References}

Akima H, Kano Y, Enomoto Y, Ishizu M, Okada M, Oishi Y, Katsuta S, Kuno S (2001) Muscle function in 164 men and women aged 20-84 yr. Med Sci Sports Exerc 33: 220-226

Akima H, Kuno S, Suzuki Y, Gunji A, Fukunaga T (1997) Effects of 20 days of bed rest on physiological cross-sectional area of human thigh and leg muscles evaluated by magnetic resonance imaging. J Gravit Physiol 4: S15-21

Allen TH, Andersen EC, Langham WH (1960) Total body potassium and gross body composition in relationship to age. J Gerontol 15: 348-357

Andersson E, Oddsson L, Grundström H, Thorstensson A (1995) The role of the psoas and iliacus muscles for stability and movement of the lumbar spine, pelvis and hip. Scand J Med Sci Sports 5:10-16

Arts IM, Pillen S, Schelhaas HJ, Overeem S, Zwarts MJ (2010) Normal values for quantitative muscle ultrasonography in adults. Muscle Nerve 41: 32-41

Bemben MG, Massey BH, Bemben DA, Misner JE, Boileau RA (1991) Isometric force production as a function of age in healthy 20- to 74-yr-old men. Med. Sci. Sports Exerc 23:1302-1310

Berg HE, Larsson L, Tesch PA (1997) Lower limb skeletal muscle function after 6 wk of bed rest. J Appl Physiol 82: 182-188

Blazevich AJ, Gill ND, Zhou S (2006) Intra- and intermuscular variation in human quadriceps femoris architecture assessed in vivo. J Anat $209: 289-310$

Booth FW (1982) Effect of limb immobilization on skeletal muscle. J Appl Physiol 52:1113-1118

Brooks SV, Faulkner JA (1994) Skeletal Muscle Weakness in Old Age: Underlying Mechanisms. Med. Sci. Sports Exercise 26: 432-439

Buchner DM, Larson EB, Wagner EH, Koepsell TD, de Lateur BJ (1996) Evidence for a non-linear relationship between leg strength and gait speed. Age Ageing 25: 386-391

Doherty TJ, Vandervoort AA, Brown WF (1993) Effects of Ageing on the Motor Unit: A Brief Review. Can J Appl Physiol 18, 331-358

Dupont AC, Sauerbrei EE, Fenton PV, Shragge PC, Loeb GE, Richmond FJ (2001) Real-time sonography to estimate muscle thickness: comparison with MRI and CT. J Clin Ultrasound 29:230-236 
Ferrando AA, Stuart CA, Brunder DG, Hillman GR (1995) Magnetic resonance imaging quantitation of changes in muscle volume during 7 days of strict bed rest. Aviat Space Environ Med 66:976-981

Ferrucci L, Guralnik JM, Buchner D, Kasper J, Lamb SE, Simonsick EM, Corti MC, Bandeen-Roche K, Fried LP (1997) Departures from linearity in the relationship between measures of muscular strength and physical performance of the lower extremities: the Women's Health and Aging Study. J Gerontol A Biol Sci Med Sci 52: M275-285

Fujiwara K, Asai H, Toyama H, Kunita K, Yaguchi C, Kiyota N, Tomita H, Jacobs JV (2010) Changes in muscle thickness of gastrocnemius and soleus associated with age and sex. Aging Clin Exp Res 22, 24-30

Fukunaga T, Miyatani M, Tachi M, Kouzaki M, Kawakami Y, Kanehisa H(2001) Muscle volume is a major determinant of joint torque in humans. Acta Physiol Scand 172:249-255

Hides JA, Belavý DL, Stanton W, Wilson SJ, Rittweger J, Felsenberg D, Richardson CA (2007) Magnetic resonance imaging assessment of trunk muscles during prolonged bed rest. Spine 32: $1687-1692$

Hikida RS, Gollnick PD, Dudley GA, Convertino VA, Buchanan P (1989) Structural and metabolic characteristics of human skeletal muscle following 30 days of simulated microgravity.Aviat Space Environ Med 60: 664-670

Janssen I, Heymsfield SB, Wang Z, Ross R (2000) Skeletal muscle mass and distribution in 468 men and women aged 18-88 yr. J Appl Physiol 89: 81-88

Johnson MA, Polgar J, Weightman D, Appleton D (1973) Data on the distribution of fibre types in thirty-six human muscles. An autopsy study. J Neurol Sci 18: 111-129.

Kellis E, Galanis N, Natsis K, Kapetanos G (2009) Validity of architectural properties of the hamstring muscles: correlation of ultrasound findings with cadaveric dissection. J Biomech. 13;42(15):2549-2554

Kubo K, Kanehisa H, Azuma K, Ishizu M, Kuno SY, Okada M, Fukunaga T (2003a) Muscle architectural characteristics in women aged 20-79 years. Med Sci Sports Exerc 35: 39-44

Kubo K, Kanehisa H, Azuma K, Ishizu M, Kuno SY, Okada M, Fukunaga T (2003b) Muscle architectural characteristics in young and elderly men and women. Int J Sports Med 24: $125-130$

Kwon IS, Oldaker S, Schrager M, Talbot LA, Fozard JL, Metter EJ (2001) Relationship between muscle strength and the time taken to complete a standardized walk-turn-walk test. J Gerontol A Biol Sci Med Sci 56A:B398-B404

Lexell J, Taylor CC, Sjostrom M (1988) What is the cause of the ageing atrophy? Total number, size and proportion of different fiber types studied in whole vastus lateralis muscle from $15-$ to 83-year-old men. J Neurol Sci 84: 275-294

Macaluso A, De Vito G (2004) Muscle strength, power and adaptations to resistance training in older people. Eur J Appl Physiol 91:450-472

Maganaris CN, Baltzopoulos V, Sargeant AJ (1998) In vivo measurements of the triceps surae complex architecture in man: implications for muscle function. J Physiol 512:603-614 
Miyatani M, Kanehisa H, Ito M, Kawakami Y, Fukunaga T (2004) The accuracy of volume estimates using ultrasound muscle thickness measurements in different muscle groups. Eur J Appl Physiol 91:264-272

Narici MV, Binzoni T, Hiltbrand E, Fasel J, Terrier F, Cerretelli P (1996) In vivo human gastrocnemius architecture with changing joint angle at rest and during graded isometric contraction. J Physiol 496:287-297

Ohira Y, Jiang B, Roy RR, Oganov V, Ilyina-Kakueva E, Marini JF, Edgerton VR (1992) Rat soleus muscle fiber responses to 14 days of spaceflight and hindlimb suspension. J Appl Physiol 73(2 Suppl):51S-57S

Park H, Park S, Shephard RJ, Aoyagi Y (2010) Yearlong physical activity and sarcopenia in older adults: the Nakanojo Study. Eur J Appl Physiol 25 [Epub ahead of print]

Rantanen T, Guralnik JM, Izmirlian G, Williamson JD, Simonsick EM, Ferrucci L, Fried LP (1998) Association of muscle strength with maximum walking speed in disabled older women. Am J Phys Med Rehabil 77: 299-305

Reeves ND, Maganaris CN, Narici MV (2004) Ultrasonographic assessment of human skeletal muscle size. Eur J Appl Physiol 91: 116-118

Reimers CD, Harder T, Saxe H (1998) Age-related muscle atrophy does not affect all muscles and can partly be compensated by physical activity: an ultrasound study. J Neurol Sci 159:60-66

Roos MR, Rice CL, Vandervoort AA (1997) Age-related changes in motor unit function. Muscle Nerve 20:679-690

Sanada K, Kearns C, Midorikawa T, Abe T (2006) Prediction and validation of total and regional skeletal muscle mass by ultrasound in japanese adults. Eur J Appl Physiol 96: 24-31

Sandler RB, Burdett R, Zaleskiewicz M, Sprowls-Repcheck C, Harwell M (1991) Muscle strength as an indicator of physical activity. Med. Sci. Sports Exerc 23:1375-1381

Shimada H, Suzukawa M, Tiedemann A, Kobayashi K, Yoshida H, Suzuki T (2009) Which neuromuscular or cognitive test is the optimal screening tool to predict falls in frail community-dwelling older people? Gerontology. 55:532-538

Templeton GH, Sweeney HL, Timson BF, Padalino M, Dudenhoeffer GA (1988) Changes in fiber composition of soleus muscle during rat hindlimb suspension. J Appl Physiol 65:1191-1195

Thoirs K, English C (2009) Ultrasound measures of muscle thickness: intra-examiner reliability and influence of body position. Clin Physiol Funct Imaging 29:440-446

Walton JM, Roberts N, Whitehouse GH (1997) Measurement of the quadriceps femoris muscle using magnetic resonance and ultrasound imaging. Br J Sports Med 31: 59-64

Young A, Stokes M, Crowe M (1985) The size and strength of the quadriceps muscles of old and young men. Clin Physiol 5: 145-154 
Table 1

Characteristics of the elderly subjects (mean \pm S.D.)

\begin{tabular}{lccc}
\hline & $\begin{array}{c}\text { Fast-walking } \\
\text { group }\end{array}$ & $\begin{array}{c}\text { Slow-walking } \\
\text { group }\end{array}$ & Dependent group \\
\hline Number & 14 & 11 & 12 \\
Age (years) & $83.1 \pm 5.7$ & $85.5 \pm 6.8$ & $88.1 \pm 5.5$ \\
Height $(\mathrm{m})$ & $1.47 \pm 0.07$ & $1.44 \pm 0.07$ & $1.41 \pm 0.07$ \\
Weight $(\mathrm{kg})$ & $45.0 \pm 6.8^{* *}$ & $45.1 \pm 8.8^{* *}$ & $32.8 \pm 4.5$ \\
BMI $\left(\mathrm{kg} / \mathrm{m}^{2}\right)$ & $21.0 \pm 3.5^{* *}$ & $21.8 \pm 3.9^{* *}$ & $16.5 \pm 1.9$ \\
\hline
\end{tabular}

${ }^{* *}, \mathrm{p}<0.01$ significant difference for the dependent group 
Table 2

Measurement positions and measurement sites for each muscle

\begin{tabular}{|c|c|c|}
\hline Muscles & Positions & Measurement sites \\
\hline Gluteus maximus & Prone & $\begin{array}{l}30 \% \text { proximal between posterior superior iliac spine the } \\
\text { greater trochanter }\end{array}$ \\
\hline Gluteus medius & Prone & $\begin{array}{l}\text { Midway between the proximal end of iliac crest and the } \\
\text { greater trochanter }\end{array}$ \\
\hline Gluteus minimus & Prone & $\begin{array}{l}\text { Midway between the proximal end of iliac crest and the } \\
\text { greater trochanter }\end{array}$ \\
\hline Psoas major & Prone & $7 \mathrm{~cm}$ lateral from the $\mathrm{L} 3$ spinous process \\
\hline Rectus femoris & Supine & $\begin{array}{l}\text { Midway between the anterior superior iliac spine and the } \\
\text { proximal end of the patella }\end{array}$ \\
\hline Vastus lateralis & Supine & $\begin{array}{l}3 \mathrm{~cm} \text { lateral of } 60 \% \text { distal between the anterior superior iliac } \\
\text { spine and the proximal end of the patella }\end{array}$ \\
\hline $\begin{array}{c}\text { Vastus } \\
\text { intermedius }\end{array}$ & Supine & $\begin{array}{l}\text { Midway between the anterior superior iliac spine and the } \\
\text { proximal end of the patella }\end{array}$ \\
\hline Biceps femoris & Prone & $\begin{array}{l}\text { Midway between the ischial tuberosity and the lateral } \\
\text { condyle of the tibia }\end{array}$ \\
\hline Gastrocnemius & Prone & $\begin{array}{l}\text { Medial head of gastrocnemius at } 30 \% \text { proximal between the } \\
\text { lateral malleolus of the fibula and the lateral condyle of the } \\
\text { tibia }\end{array}$ \\
\hline Soleus & Prone & $\begin{array}{l}30 \% \text { proximal between the lateral malleolus of the fibula } \\
\text { and the lateral condyle of the tibia }\end{array}$ \\
\hline
\end{tabular}




\section{Figure 1}

Representative ultrasound image of gastrocnemius and soleus

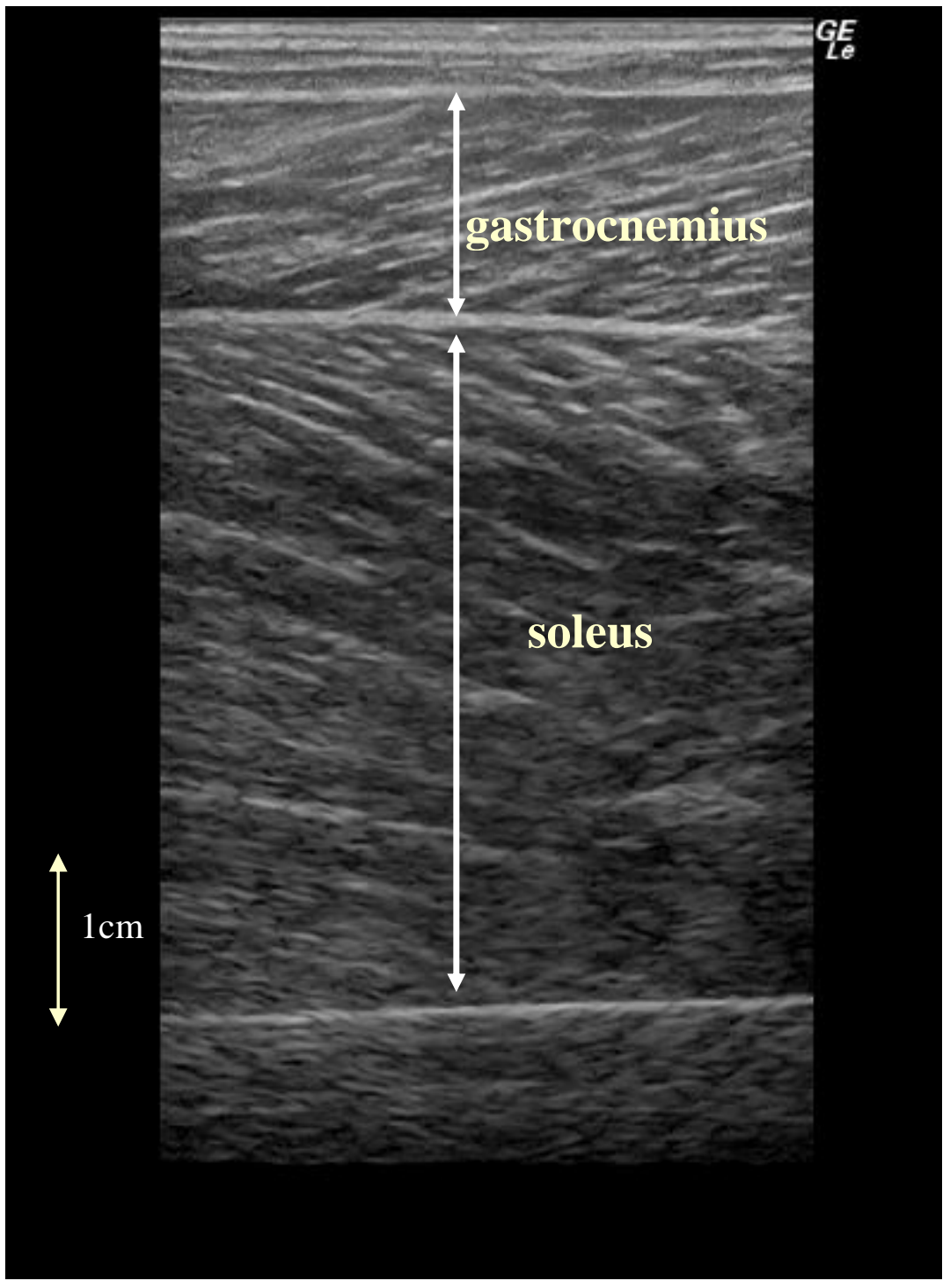


Table 3

Comparison of muscle thickness $(\mathrm{mm})$ between the young and elderly groups

\begin{tabular}{lllll}
\hline & Young & $\begin{array}{l}\text { Fast -walking } \\
\text { group }\end{array}$ & $\begin{array}{l}\text { Slow-walking } \\
\text { group }\end{array}$ & Dependent group \\
\hline Gluteus maximus & $25.0 \pm 2.98$ & $14.9 \pm 3.56^{* *}$ & $14.7 \pm 4.46^{* *}$ & $8.60 \pm 2.42^{* *}$ \\
Gluteus medius & $22.9 \pm 5.80$ & $15.0 \pm 4.16^{* *}$ & $14.6 \pm 3.97^{* *}$ & $9.69 \pm 2.23^{* *}$ \\
Gluteus minimus & $19.3 \pm 6.47$ & $12.8 \pm 4.08^{* *}$ & $12.3 \pm 4.36^{* *}$ & $9.54 \pm 1.76^{* *}$ \\
Psoas major & $28.7 \pm 4.11$ & $13.0 \pm 5.58^{* *}$ & $15.0 \pm 2.93^{* *}$ & $10.9 \pm 4.07^{* *}$ \\
Rectus femoris & $22.9 \pm 3.39$ & $16.7 \pm 3.50^{* *}$ & $15.4 \pm 5.42^{* *}$ & $4.08 \pm 1.36^{* *}$ \\
Vastus lateralis & $22.0 \pm 3.25$ & $14.1 \pm 3.76^{* *}$ & $12.2 \pm 3.08^{* *}$ & $3.73 \pm 1.26^{* *}$ \\
Vastus intermedius & $21.5 \pm 3.52$ & $16.9 \pm 2.99^{* *}$ & $12.8 \pm 4.68^{* *}$ & $4.69 \pm 2.39^{* *}$ \\
Biceps femoris & $36.5 \pm 4.87$ & $17.9 \pm 5.01^{* *}$ & $17.1 \pm 3.83^{* *}$ & $11.2 \pm 4.40^{* *}$ \\
Gastrocnemius & $16.3 \pm 2.31$ & $10.8 \pm 2.63^{* *}$ & $10.5 \pm 4.01^{* *}$ & $7.04 \pm 1.67^{* *}$ \\
Soleus & $34.5 \pm 6.11$ & $29.8 \pm 8.25$ & $27.1 \pm 4.93$ & $17.6 \pm 6.26^{* *}$ \\
\hline
\end{tabular}

Values are expressed as means \pm the standard deviation (SD)

${ }^{* *}, \mathrm{p}<0.01$ significant difference with young group 
Table 4

Comparison of the magnitude of age-related decline (\%) between the elderly groups

\begin{tabular}{llll}
\hline & fast walking & slow walking & dependent \\
\hline Gluteus maximus & $40.3 \pm 14.8$ & $41.0 \pm 17.9$ & $65.5 \pm 10.2^{* * \dagger \dagger}$ \\
Gluteus medius & $34.7 \pm 18.9$ & $36.1 \pm 17.3$ & $57.7 \pm 10.2^{* * \dagger \dagger}$ \\
Gluteus minimus & $33.9 \pm 21.9$ & $36.4 \pm 22.6$ & $50.6 \pm 9.51$ \\
Psoas major & $54.8 \pm 20.1$ & $45.9 \pm 10.2$ & $62.3 \pm 14.8$ \\
Rectus femoris & $26.9 \pm 15.9$ & $32.8 \pm 23.7$ & $82.2 \pm 6.19^{* * \dagger \dagger}$ \\
Vastus lateralis & $36.0 \pm 17.7$ & $44.3 \pm 14.0$ & $83.0 \pm 6.00^{* * \dagger}$ \\
Vastus intermedius & $21.3 \pm 14.5$ & $40.3 \pm 21.8$ & $78.2 \pm 11.6^{* * \dagger}$ \\
Biceps femoris & $51.0 \pm 14.3$ & $53.1 \pm 10.5$ & $69.4 \pm 12.6^{* \dagger}$ \\
Gastrocnemius & $34.0 \pm 16.7$ & $35.4 \pm 24.6$ & $56.8 \pm 10.7^{* * \dagger}$ \\
Soleus & $13.5 \pm 24.8$ & $21.6 \pm 14.3$ & $49.1 \pm 18.9^{* * \dagger}$ \\
\hline
\end{tabular}

Values are expressed as means \pm the standard deviation(SD)

${ }^{* *}, \mathrm{p}<0.01,{ }^{*}, \mathrm{p}<0.05$ significant difference with fast-walking group

${ }^{\dagger}, \mathrm{p}<0.01,{ }^{\dagger}, \mathrm{p}<0.05$ significant difference with slow-walking group 
Table 5

Differences in the t-score between muscles in the elderly groups

\begin{tabular}{llll}
\hline & fast walking & slow walking & dependent \\
\hline Gluteus maximus & $-3.13 \pm 1.16^{\mathrm{a}}$ & $-3.19 \pm 1.39$ & $-5.09 \pm 0.79^{\mathrm{b}}$ \\
Gluteus medius & $-1.37 \pm 0.74$ & $-1.42 \pm 0.68$ & $-2.28 \pm 0.40$ \\
Gluteus minimus & $-1.01 \pm 0.65$ & $-1.08 \pm 0.67$ & $-1.51 \pm 0.28$ \\
Psoas major & $-3.84 \pm 1.41^{\mathrm{b}}$ & $-3.22 \pm 0.72^{\mathrm{b}}$ & $-4.37 \pm 1.04^{\mathrm{c}}$ \\
Rectus femoris & $-1.82 \pm 1.07$ & $-2.22 \pm 1.60$ & $-5.55 \pm 0.42^{\mathrm{d}}$ \\
Vastus lateralis & $-2.47 \pm 1.22$ & $-3.04 \pm 0.96$ & $-5.70 \pm 0.41^{\mathrm{d}}$ \\
Vastus intermedius & $-1.75 \pm 1.64$ & $-2.62 \pm 1.42$ & $-5.10 \pm 0.76^{\mathrm{b}}$ \\
Biceps femoris & $-3.80 \pm 1.06^{\mathrm{b}}$ & $-3.96 \pm 0.78^{\mathrm{b}}$ & $-5.17 \pm 0.94^{\mathrm{b}}$ \\
Gastrocnemius & $-2.40 \pm 1.18$ & $-2.50 \pm 1.74$ & $-4.01 \pm 0.76^{\mathrm{c}}$ \\
Soleus & $-0.76 \pm 1.40$ & $-1.22 \pm 0.81$ & $-2.77 \pm 1.07$ \\
\hline
\end{tabular}

Values are expressed as means \pm the standard deviation(SD)

${ }^{a}$ significant difference with soleus and gluteus minimus

${ }^{\mathrm{b}}$ significant difference with soleus, gluteus minimus and gluteus medius

${ }^{c}$ significant difference with gluteus minimus and gluteus medius

${ }^{\mathrm{d}}$ significant difference with soleus, gluteus minimus, gluteus medius and gastrocnemius 